Withanage, I.M., Zainudeen, N. and Nadeeshani, M., 2019. Financial viability of using green roofing in residential buildings. In: Sandanayake, Y.G., Gunatilake, S. and Waidyasekara, A. (eds). Proceedings of the $8^{\text {th }}$ World Construction Symposium, Colombo, Sri Lanka, 8-10 November 2019, pp. 350-359. DOI: doi.org/10.31705/WCS.2019.35. Available at: https://2019.ciobwcs.com/papers

\title{
FINANCIAL VIABILITY OF USING GREEN ROOFING IN RESIDENTIAL BUILDINGS
}

\author{
Isuru Madhawa Withanage ${ }^{1}$, Niza Zainudeen ${ }^{2}$ and Malka Nadeeshani ${ }^{3}$
}

\begin{abstract}
As a result of increased attention towards sustainability worldwide, green concepts have become popular in the construction industry. Green roof is one of the essential elements in a green building that provide many advantages while creating a pleasant appearance for the total building. Green roofs play a major role in energy saving of a building. However, compared to a conventional roof, the initial and maintenance costs of a green roof is quite high due to the additional construction and high maintenance requirements. Thus, this paper compares the Life Cycle Cost (LCC) of a green roof with that of a conventional ceramic tile roof in order to determine the financial viability of green roofing. Findings were gathered from several cases and past researches under initial cost, maintenance cost and energy saving of green roofs and adopted to the selected case for the analysis. Findings of the study indicate that initial cost of the green roof was higher than conventional and represented 8.39:(-6.55) proportion of the total life cycle cost of the building. Similarly, maintenance, operational and replacement costs were also higher than the conventional representing 12.08:(-6.55) proportion of the total life cycle cost of the building. Green roof also had higher energy cost than the conventional, representing (-23.64):(-6.55) proportion of total life cycle cost of the building. As a result, it was found that (-Rs. $11,654.70) / \mathrm{m}^{2}$ net saving by a green roof is considerable despite of the high initial and the maintenance cost. According to the study, green roofing concept is financially and environmentally beneficial concept even though there are some barriers, like lack of knowledge, lack of techniques, lack of standards in implementing this concept in the Sri Lankan context. Hence, it is recommended to use green roofing in residential buildings.
\end{abstract}

Keywords: Energy Saving; Green Roof; Green Roof Cost; Life Cycle Cost.

\section{INTRODUCTION}

Since climate change is a vast environmental issue in $21^{\text {st }}$ century, it has been stated that the climatic change can be named as a deviation of the global climate due to the growing average global temperature (Intergovernmental Panel on Climate Change, 2013; Cook, 2017). Further, it has predicted that the net annual cost on damage expenses of climate changes will rise due to this increment of the global temperature (The Earth Science Communications Team at Nasa' Jet Populsion Labority, 2017). Hence, scientists and engineers have been searching a better explanation to overcome the effects of global warming in the modern world over last few decades (Dareeju et al., 2011). However, Sustainable development has overtaken the need of seeking the solutions, through a

\footnotetext{
${ }^{1}$ Department of Building Economics, University of Moratuwa, Sri Lanka, impwithanage@gmail.com

2 Department of Building Economics, University of Moratuwa, Sri Lanka, nisazd2014@gmail.com

${ }^{3}$ Department of Building Economics, University of Moratuwa, Sri Lanka, malkanadeeshani94@gmail.com
} 
mechanism of meeting the human development goals in natural ways (Kazi and Kazi, 2016). Subsequently, green building concept gives a greater level of environmental, economic and engineering performance within the construction sector (Samer, 2013).

As per the Green Building Council of Sri Lanka (2015), the green building is a building which uses low energy and water as well as increasing the indoor air quality. Respectively, green roofing is a one of effective technique to be followed in the term of green building concept. The origin of green roofs may drive back to the $79 \mathrm{AD}$ and it has initiated as a roof garden (Ahmed and Alibaba, 2016). Further, The Hanging Gardens of Babylon is one of the most famous green roofs in the world which was constructed in 500 BC (Lawrence Technological University, 2006). However, the modern roofing concept was started in Germany in 1960s, where vegetation was grown on the roofs to mitigate effect of solar radiation (Oberndorfer et al., 2007; Fellows, 2012).

Even though vegetated roofs can be identified as one of the substitutes for land covering method which can give various economic benefits in urban city area, Blackhurst et al. (2010) have pointed out that the cost of green roofing is not economical (Carter and Butler, 2008). However, the challenges like initial high construction cost and high maintenance cost are deemed to associate with the green roofs. Blackhurst et al. (2010) have further explained that the cost will be reasonable when the social benefits are included. Also, it is an obligation of occupants to maintain the roof garden well, despite the fact that it incurs high maintenance cost (Klinkenborn, 2009). Thus, this paper aims to appraise the financial costs and benefits of green roofing during its life cycle including the analysis of the energy saving that could accrue by green roofs.

\section{LITERATURE REVIEW}

\subsection{COMPONENTS AND TYPES OF GREEN ROOFING}

A green roof consists of several layers namely plant/ vegetation layer, growing medium, filter layer, Drainage layer, protection layer and waterproofing layer. These components can further divide into two main categories as living component and structural component, where the vegetation layer and growing medium considers as living component. Even though, Sedum plants were used as main vegetation layer in most of the green roof gardens, use of various plantations is helpful to increase the effectiveness of the green roof (Wolf and Lundholm, 2008; Fellows, 2012). Generally, growing medium includes $80 \%$ of a lightweight inorganic material and the remaining is an organic material (Beattie and Bergharge, 2004).

Various types of green roofs have been used in different countries under different weather conditions. (Williams et al., 2010). While, extensive and intensive are the two major types, generally 3 types of green roofs can be identified as intensive, extensive and semi intensive according to the Department of Energy-USA (2004). Extensive roofing is a lightweight system where the build-up height of the layers is less than $100 \mathrm{~mm}$ and the maintenance requirement is low (The Green Roof Center in UK, 2011). Intensive green roofs are like a garden or park with plants, trees and bushes, where the depth of the substrate is greater than 200mm (The Climate Protection Partnership Division in the U.S. Environmental Protection Agency's Office of Atmospheric Programs, n.d.). Respectively, semi intensive green roof; a combination of the both types, carries $100 \mathrm{~mm}$ to 200mm substrate depth (Department of Planning and Local Government, 2010). 


\subsection{BENEFITS OF GREEN ROOFING}

According to Sadeghian (2017), green roof gives ecological, aesthetic and financial benefits. Further, there were policies used to promote green roofing as a part of sustainable concept mainly due to these benefits of the green roofing concept (Sutton, 2015). Some of benefits of green roofing are as follows.

- Urban heat island mitigation

- Thermal insulation with reduced building energy costs

- Expanding the urban storm water management

- Enhancing the aesthetic of cityscapes

- Increasing the wildlife habitat

\subsection{BARRIERS TO GREEN ROOFING}

The barriers will drive any concept away if those barriers were not identified and treated properly. The review of literature summarises the barriers in adopting green roofing as follows (Townshend, 2007; Ngan, 2004).

- Lack of knowledge and awareness

- Technical difficulty during the design and construction

- Lack of standards

- Difficulties in repairs

- Cost of the green roofing

- Absence of government regulation

\subsection{Life Cycle Costing}

Life Cycle Costing (LCC) is an economic analysis which is used in selecting cost effective alternatives (U.S.General Service Administration, 2017). The elements of LCC are initial capital costs, life of the asset, the discount rate, operating and maintenance costs, disposal cost, information and feedback, uncertainty and sensitivity analysis (Woodward, 1997). In LCC technique, all their future costs and benefits are identified and bring them to their present values (Peri et al., 2012).

\section{RESEARCH METHODOLOGY}

This study was conducted under three main phases. Firstly, a comprehensive literature synthesis was carried out to review the concept of green roofing, types of green roofs, benefits and barriers of green roof. Secondly, preliminary interviews and site visits were conducted to obtain a better understanding on green roofs in Sri Lanka as it is relatively a new concept. Under the preliminary interviews, an expert who involved in one of famous roof gardens was interviewed. In the site visit and the preliminary interview, information related to construction methodologies and materials details were collected.

The type of intensive green roofs was the target green roofing concept of this research study. Therefore, as the third step, a case study was undertaken to perform the comparative LCC analysis between traditional and intensive green roofing systems. The Table 1 presents the steps followed in performing the comparative LCC analysis. 
Table 1: Steps followed in data collection

\begin{tabular}{ll}
\hline \multicolumn{1}{c}{ Step } & \multicolumn{1}{c}{ Related Action } \\
\hline $\begin{array}{l}\text { Identify and analyse the } \\
\text { initial costs, maintenance } \\
\text { and replacement costs }\end{array}$ & $\begin{array}{l}\text { From selected cases } \\
\text { To calculate the initial cost, the proposed green roof was used. } \\
\text { This green roof has } 5 \text { cost proposals and by using these cost } \\
\text { proposals initial cost was calculated. } \\
\text { To calculate, maintenance and replacement cost, separate } \\
\text { projects were used. By using } 2 \text { separate projects in Galle and } \\
\text { Colombo average maintenance and replacement cost were } \\
\text { calculated. }\end{array}$ \\
\hline $\begin{array}{l}\text { Analyse the energy saving } \\
\text { that could accrue due to } \\
\text { green roofs. }\end{array}$ & $\begin{array}{l}\text { By comparing the electricity consumption of air conditioning of } \\
\text { non-green roof building (ceramic tile roof) and green roof, the } \\
\text { energy saving was calculated. }\end{array}$ \\
& To calculate above details, top floor of the apartment complex \\
& was used. There was 5 condominiums and one was not in a \\
regular use. So, remaining four apartments were used. Out of \\
those 4, two were A/C apartments and remaining two were non \\
A/C apartments. \\
So, by considering electrical consumption of each condominium \\
for one year, additional cost for the A/C was calculated. \\
That will be the energy saving if the A/C requirement was \\
avoided. Theoretical calculation used to get the green roof \\
energy saving.
\end{tabular}

\section{RESEARCH FINDINGS AND DISCUSSION}

In the research findings, green roof was proposed to roof top of the condominium building. The area of the roof was $791.05 \mathrm{~m}^{2}$. The green roof has been applied to an area of $562.43 \mathrm{~m}^{2}$. The rest of the area was covered with staircase. 


\subsection{COMPARISON OF INITIAL COST}

Since initial cost represents one of the core elements of LCC, the initial cost was identified based on the cost of similar kind of green roofs which were located in the same area. There were five cost estimates for green roofs which were used for calculating initial cost. The average rate per unit of each material of green roofs were considered, while excluding the considerable rate deviations of materials. After measuring the unit quantities of each material with the help of drawings and specifications, initial cost of each type of roofs were quantified. By using those details, the initial unit cost was calculated. Based on the calculated initial unit cost of green roof, the cost of the proposed green roof was estimated.

In the selected roof, there was ceramic tiles finishing. Most of the high-rise condominiums have ceramic tile finish. Thus, research was continued with the ceramic tile roof. Based on actual construction details, the cost of the ceramic tiles was identified.

The initial cost of the green roof and ceramic tile finished roof for the selected roof are as follows.

- Initial cost of Green roof

Rs. $5,011,408.78$

- Initial cost of Ceramic tile roof

Rs. $2,469,067.70$

This confirms the fact that green roof incurs more initial investment than conventional roofs.

\subsection{COMPARISON OF MAINTENANCE AND REPLACEMENT COST}

Maintenance and replacement cost of green roofs have been calculated using two projects which are currently being maintained and cost data was collected based on the maintenance budget records.

- Further, it has been considered that the top most vegetation layer will be removed and replaced once in every 5 years.

- Simultaneously, maintenance cost of ceramic tile cover roofing was also calculated irrespective of the replacement cost because it can be used for 30 years without any replacement.

- According to collected data, Table 2 was developed. Table 2 clearly shows that green roof has high maintenance and replacement cost than ceramic tile roofing

Table 2: Maintenance and operational cost comparison of green roof and ceramic tile finishing

\begin{tabular}{lcc}
\hline \multicolumn{1}{c}{ Type } & Maintenance Cost & Replacement Cost \\
\hline Green roof & $8,385,216.48$ & $3,687,404.91$ \\
Ceramic Tile Roof & $3,953,380.00$ & 0.00 \\
\hline
\end{tabular}

\subsection{COMPARISON OF ENERGY COST SAVING}

Few steps were undertaken to calculate the energy saving of the green roof. Based on the literature synthetises, modern cities used $\mathrm{A} / \mathrm{C}$ and fan systems to reduce temperature of buildings. However, green roofs can reduce temperature of the building by a considerable amount. So, the energy cost saving was calculated based on the electrical (energy) cost of the $\mathrm{A} / \mathrm{C}$ and the fan cost of the ceramic tile building and the temperature reduction of green building. 
While calculating additional energy cost of the conventional roofing building, the number of occupancies need to consider because the electrical consumption was depending on the number of occupancies. Both $\mathrm{A} / \mathrm{C}$ and Non-A/C rooms, there was same number of occupancies in the apartments. So, occupancy number did not affect the calculation. Base on the analysis, additional cost of $\mathrm{A} / \mathrm{C}$ was identified based on current tariff rates. That is the energy saving if $\mathrm{A} / \mathrm{C}$ was not used.

The average electrical consumption of non-A/C apartments per month $=210.00 \mathrm{kWh}$. So, the average electrical tariff of non - $\mathrm{A} / \mathrm{C}$ apartments of the selected project were calculated according to the electricity board norms and it was Rs. 5413.50.

The average electrical consumption of the $\mathrm{A} / \mathrm{C}$ apartments per month $=690.83 \mathrm{kWh}$. The average electrical tariff of $\mathrm{A} / \mathrm{C}$ apartments of the selected project was calculated according to the electricity board norms and it was Rs. 27,050.85.

$$
\begin{aligned}
\text { Additional cost for Air Conditioning apartment } & =\text { Rs. } 27,050.85-\text { Rs. } 5,413.50 \\
& =\text { Rs. } 21,637.35
\end{aligned}
$$

Based on previous researches, the temperature reduction was identified (as the current study did not collect those data due to time constraint). Based on thermal conductivity of the materials, and the temperature reduction in ceramic tile roof and the green roof, the $\mathrm{A} / \mathrm{C}$ cost of the green roof was calculated as Rs. 46,779.38. The calculation was done based on equations (01) and (02) given below.

$$
\begin{aligned}
& Q=K A(T 2-T 1) / L \\
& Q=A(T 2-T 1) /((L 1 / K 1)+(L 2 / K 2)+(L 3 / K 3))
\end{aligned}
$$

Where;

$\mathrm{Q}=$ Heat Transfer

$\mathrm{K} / \mathrm{K} 1, \mathrm{~K} 2, \mathrm{~K} 3$ = Thermal Conductivity

$\mathrm{A}=$ Considered Area

L/ L1, L2, L3 = Thickness of the material

T $2=$ Temperature of Outer face

$\mathrm{T} 1=$ Temperature of Inner face

A/C Energy Saving in the green building = Rs. 259,648.20 - Rs. 46,779.38

$=$ Rs. $212,868.82$

This amount is comparative amount with ceramic tile roof. So, Energy saving of the ceramic tile cover roof was considered as Zero. There was some energy saving with ceramic tile cover roof when it was compared with slab.

\subsection{LCC COMPARISON BETWEEN GREEN AND CONVENTIONAL ROOFS}

When calculating LCC, initial cost, repair and maintenance cost and the energy saving were already calculated. The next step involved, discounting where discounting factor was calculated considering average interest rate and the inflation rate. To calculate average inflation rate, past 20 years was considered, and abnormal deviated years was removed from the calculation. So, average inflation rate calculated was $6.54 \%$. 
When calculating interest rate, savings interest rate and lending interest rate was considered. According to bank details, the lending percentage for housing projects is $75 \%$. So, remaining $25 \%$ must invest by the customer.

Base on above factor and 20 years lending and savings ratios, the average interest rate was calculated.

- Average savings interest rate $=8.17 \%$

- Average lending interest rate $=14.54 \%$

According to bank data, the proportion between lending rate and savings rate is $75 \%$ : $25 \%$. So average interest rate is $12.95 \%$.

Based on the calculated average inflation rate $(\mathrm{g})$ and average interest rate $(\mathrm{r})$, discounting rate (I) was calculated using equation (03).

$$
\begin{aligned}
I & =((1+r) /(1+g)+1) \times 100 \% \\
& =(1+12.95 \%) /(1+6.54 \%)+1) 100 \% \\
& =2.06 \%
\end{aligned}
$$

Then the LCC was carried out and identified the most economical roofing type. The calculation was done for 30 years and the life spam of ceramic tile finishing roof was considered 30 years and green roof has 5-year major repairs and finally life span ends in 30 years. That means after 30 years, there was no value of both roofing systems. In the LCC calculation, the base year was considered 2018.

In the LCC calculation, cost values were considered positive and benefits were considered

\begin{tabular}{|c|c|c|c|c|}
\hline Stage & $\begin{array}{c}\text { Discounting } \\
\text { Factor } \\
(\mathbf{2 . 0 6 \% )}\end{array}$ & $\begin{array}{c}\text { Green Roof (Net } \\
\text { Present Value) } \\
\text { Rs. }\end{array}$ & $\begin{array}{l}\text { Discounting } \\
\text { Factor } \\
(2.06 \%)\end{array}$ & $\begin{array}{l}\text { Ceramic Tile Roof } \\
\text { (Net Present } \\
\text { Value) Rs. }\end{array}$ \\
\hline Initial Cost & 1 & $5,011,408.78$ & 1 & $2,469,067.70$ \\
\hline $\begin{array}{l}\text { Operational \& } \\
\text { Maintenance cost }\end{array}$ & 22.21 & $8,385,216.48$ & 22.21 & $3,953,380.00$ \\
\hline Replacement cost & 3.72 & $3,687,404.91$ & 0 & 0.00 \\
\hline Energy Cost & 22.21 & $(23,639,082.46)$ & 0 & 0.00 \\
\hline LCC & & $(6,555,052.29)$ & & $6,422,447.70$ \\
\hline
\end{tabular}
negative.

Table 3: Comparison of LCC between green roof and ceramic tile roof

Figure 1 shows the graphical representation of the LCC differences between green roof and ceramic tile finishing.

The limitations and assumptions used in the analysis include:

- The accuracy of the calculation is subjected to available data. There were only few numbers of green usage and the data were collected from those few projects.

- Lack of historical data available as the use of green roofing is relatively new to the country.

- In the calculation of some factors, only a few number of projects were considered. 
- The economic life of the building was assumed as 30 years. This might vary according to physical factors.

- The accuracy of electrical consumption of $\mathrm{A} / \mathrm{C}$ is little questionable as there was no any standard method to calculate the exact electrical consumption by $\mathrm{A} / \mathrm{C}$.

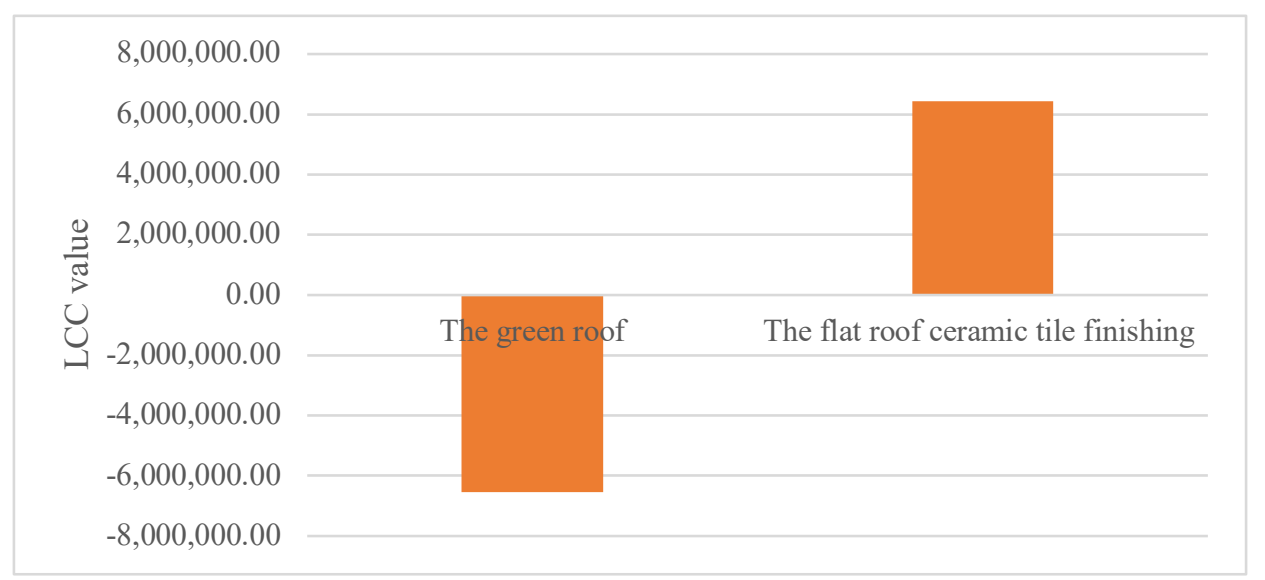

Figure 1: LCC comparison between green roof and ceramic tile roofing

\section{CONCLUSIONS AND RECOMMENDATIONS}

The urbanization process and the growth of urban areas have increased in recent years. As a result, many natural landscapes have been destructed and many adverse effects have arisen. Among all the adverse effects, less greenery areas, air pollution, drainage problems, urban heat island effect and decrement of natural wildlife habitats have majorly effected to urban areas, citizens and wildlife. Several new concepts have proposed in mitigating these adverse effects where the green roof becomes one alternative to address these issues.

When consider the green roofing, it can be applied for roof slab covering in buildings. Green roof has higher initial cost and replacement cost than other slab covering methods. However, there will be a huge energy saving because of the reduction of cooling cost of the building. The requirement of cooling method is minimized in buildings having green roofs.

This energy saving was calculated by using LCC method. When calculating LCC, to get more fair result, average rates were considered to determine the discounting factor.

According to the outcome of the study, the LCC of ceramic tile cover was Rs. $\mathbf{6 , 4 2 2 , 4 4 7 . 7 0}$ for $\mathbf{5 6 2 . 4 3} \mathbf{~ m}^{2}$. That means the LCC per $\mathrm{m}^{2}$ is Rs. $11,419.1 / \mathrm{m}^{2}$. The LCC of the green roof was (-Rs. 6,555,052.29) for selected area, which gives LCC per $\mathrm{m}^{2}(-$ Rs. 11,654.70) $/ \mathrm{m}^{2}$. Accordingly, it can be seen that there was Rs. $23,073.80 /=$ cost benefit when the green roof is installed as the roof cover.

Based on the results of the study, green roofing concept can be recommended as an appropriate roofing method which provides various benefits to the economic (when consider the whole life) cost, social and environmental aspects which the public community needs to be aware of. Thus, necessary actions and measures should be developed to overcome the barriers in adopting a green roof. Finally, it is expected that this study would motivate increasing investments on green roofs to create sustainable cities. 


\section{REFERENCES}

Ahmed, R.M. and Alibaba, H.Z., 2016. An Evaluation of Green roofing in Buildings. International Journal of Scientific and Research Publications, 6(1), pp.366-373.

Beattie, D. and Bergharge, R., 2004. Green roof media characteristics: The basics. Oregon: In Greening Rooftops for Sustainable Communities.

Blackhurst, M., Hendrickson, C. and Matthews, H.S., 2010. Cost-effectiveness of green roofs. Journal of Architectural Engineering, 16(4), pp.136-143.

Carter, T. and Butler, a. C., 2008. Ecological impacts of replacing traditional roofs with green roofs in two urban areas. Cities and the Environment, 1(2), p.17.

Cook, J., 2017. Global warming vs Climate Change. Retrieved from Skeptical Science. [Online] Available at: https:/www.skepticalscience.com/climate-change-globalwarming.htm

Dareeju, B., Meegahage, J. and Halwatura, R., 2011. Performance of Green Roof against the Global warming. Annual Transactions of IESL, pp. 297-302.

Department of Energy-USA, 2004. Federal Technology Alert: Green Roofs.. Washington, D.C.: Department of Energy.

Department of Planning and Local Government, 2010. Rain gardens, Green roofs and infiltration systems water sensitive urban design technical manual, Adilaide: Department of Planning and Local Government.

Fellows, M., 2012. NASA \& Green Roof Research. Washington: National Aeronautics and Space Administration.

Green Building Council Sri Lanka, 2015. The GREENSL®Rating System for built environment. Colombo: Green Building Council of Sri Lanka.

Intergovernmental Panel on Climate Change, 2013. Climate changes-2013, New York: Cambridge University Press.

Kazi, S. M. and Kazi, M. S. M., 2016. Understanding sustainable development. [Online] Available at: http://www.The energy and resource institute.com/Understanding sustainable development

Klinkenborg, V., 2009. Green roofs [Online]. In: National Geographic Magazine. Available from: http://ngm.nationalgeographic.com/2009/05/green-roofs/klinkenborg-text.

Lawrence Technological University, 2006. Stormwater Institute History of Greenroofs. [Online] Available at: https://www.ltu.edu/water/greenroofs_history.asp

Ngan, G., 2004. Green Roof Policies: Tools for Encouraging Sustainable Design. Landscape Architecture Canada Foundation, pp. 6-12.

Oberndorfer, E., Lundholm, J., Bass, B., Coffman, R.R., Doshi, H., Dunnett, N., Gaffin, S., Köhler, M., Liu, K.K. and Rowe, B., 2007. Green roofs as urban ecosystems: ecological structures, functions, and services. BioScience, 57(10), pp.823-833.

Peri, G., Traverso, M., Finkbeiner, M. and Rizzo, G., 2012. The cost of green roofs disposal in a life cycle perspective: Covering the gap. Energy, 48(1), pp.406-414.

Sadeghian, M. M., 2017. Green roof, A review of history and benefits. Science and Technology, pp.510515.

Samer, M., 2013. Towards the implementation of the Green Building concept in agricultural buildings: a literature review. Agricultural Engineering International: CIGR Journal, 15(2), pp.25-46.

Sutton, R. K., 2015. Introduction to green roof ecosystems, Lincoln: Springer International Publishing Switzerland.

The Climate Protection Partnership Division in the U.S. Environmental Protection Agency's Office of Atmospheric Programs, n.d.. Reducing urban heat islands: Compendium of compendium of strategies. Green Roofs, pp.1-26.

The Earth Science Communications Team at Nasa' Jet Populsion Labority, 2017. Global Climate Changes. [Online] Available at: https:/climate.nasa.gov/effects/ [Accessed 0711 2017].

The Green Roof Center in UK, 2011. Green Roofing Hand BooK. The green roof center.

Townshend, D., 2007. Study on green roof application in Hong Kong. Urbis Limited: Hong Kong. 
U.S.General Service Administration, 2017. GSA.gov. [Online] Available at: https://www.gsa.gov

Williams, N.S., Rayner, J.P. and Raynor, K.J., 2010. Green roofs for a wide brown land: Opportunities and barriers for rooftop greening in Australia. Urban Forestry and Urban Greening, 9(3), pp.245-251.

Wolf, D. and Lundholm, J.T., 2008. Water uptake in green roof microcosms: Effects of plant species and water availability. Ecological Engineering, 33(2), pp.179-186.

Woodward, D.G., 1997. Life cycle costing-theory, information acquisition and application. International Journal of Project Management, 15(6), pp.335-344. 